REVISTA DE DERECHO UNED, NÚM. 17, 2015

\title{
LA EXPANSIÓN YIHADISTA EN EL NORTE DE ÁFRICA RESPECTO A LA DENOMINADA POLÍTICA DE GUERRA GLOBAL CONTRA EL TERROR DE GEORGE W. BUSH
}

\section{THE NORTH AFRICAN JIHADIST EXTENSIÓN WITH RESPECT TO THE SO-CALLED GEORGE W. BUSH GLOBAL WAR ON TERRORISM POLICY}

\author{
Ana Belén Perianes Bermúdez \\ Experta en seguridad en el Mediterráneo, Próximo Oriente \\ y Oriente Medio \\ Doctora en Seguridad Internacional \\ Instituto Universitario General Gutiérrez Mellado
}

Resumen: La denominada política de guerra global contra el terrorismo implementada por la Administración de George W. Bush propició un incremento de la inseguridad internacional tras la supervivencia operativa de al-Qaeda gracias a su cambio de modelo de funcionamiento a modo de franquicias regionales.

La recuperación de la operatividad del Grupo Salafista para la Predicación y el Combate, rebautizado como al-Qaeda en el Magreb Islámico junto con la propagación por el norte de África de provincias vinculadas al denominado Estado Islámico tras la autoproclamación de las mismas por grupos afines al anterior, unidas a la pugna entre ambas organizaciones por el liderazgo de la yihad global, ocuparán buena parte de la agenda de seguridad tanto regional como global tanto al corto como medio plazo.

Abstract: The so-called global war on terrorism policy implemented by the George W. Bush Administration contributed to an increase 
of the international insecurity after the al-Qaeda operational survival thanks to its operating model change as regional nets.

The Salafist Group for Preaching and Combat effectiveness recovery, renamed as al-Qaeda in the Islamic Maghreb together with the extension of provinces linked with the so-called Islamic State in the north of Africa ater their proclamation by related groups, connected to the fight for the global yihad leadership between both organizations, will occupy a significant part of the regional and global regional security agenda in the medium and in the short term.

Palabras clave: África, denominada política de guerra global al terror de George W. Bush, al-Qaeda, organización del Estado Islámico, terrorismo yihadista.

Keywords: Africa, so-called global war on terrorism policy, alQaeda, so-called Islamic State, jihadist terrorism.

Recepción original: 13/07/2015

Aceptación original: 31/08/2015

Sumario: I. Introducción. II. La supervivencia de al-Qaeda a la denominada política de guerra global contra el terror de la Administración de George W. Bush (2001-2008). III. La estructuración global de la militancia yihadista. Septiembre de 2015. IV. Al-Qaeda en el Magreb Islámico. V. La franja del Sahel. VI. Al-Qaeda tras las revueltas árabes y la eclosión del Estado Islámico de Irak y Levante como precursor de la organización del Estado Islámico. VII. Califato. VIII. La extensión de la organización del Estado Islámico por el norte de África. IX. Conclusiones.

\section{INTRODUCCIÓN}

La guerra contra Afganistán en 2001 y la invasión a Irak en 2003 emprendidas por la Administración estadounidense de George W. Bush, así como el posterior desgaste de la situación interna de aquellos países tras las mismas, produjeron diversas consecuencias en el ámbito de la seguridad en el norte de África destacando la expansión yihadista en la región tras la descentralización operativa de al-Qaeda Central, con un incremento de los riesgos y amenazas que se analizan en la presente investigación.

Tras los ataques en suelo estadounidense del 11S, al-Qaeda se convirtió en una marca subsistiendo gracias a que sus franquicias regionales facilitaron la supervivencia operativa de la organización, forza- 
da a abandonar el modelo jerárquico y rígido mediante el cual venía funcionando debido a la respuesta que emprendieron tanto la comunidad internacional en materia de política antiterrorista como, por su parte, la Administración de George W. Bush tras la implementación de su denominada política de guerra global contra el terror.

La incorporación del salafismo yihadista al orden internacional tras la guerra contra Afganistán en 2001 y la invasión de Irak en 2003 debido a la extensión del clima de violencia y terrorismo yihadista a zonas en las que previamente no existía o su presencia era difusa o latente, junto con nuevos métodos importados de Oriente Medio, redoblaron los desafíos en materia de seguridad en el norte de África. La existencia de nuevos centros de tensión cerca de Europa, en las áreas del Mediterráneo y el norte de África, dotaron a dichas regiones de una nueva centralidad y relevancia geopolítica en las relaciones internacionales debido a que los problemas de una orilla son fácilmente exportables a la otra.

Aquellos conflictos derivaron en un incremento de la preocupación por los sistemas democráticos de la orilla norteafricana del Mediterráneo y la necesidad de incidir en mayor medida en la lucha antiterrorista de los Estados de la región. En este sentido, el salafismo yihadista originó tras el 11S una gran desconfianza entre los países de la orilla norte del Mediterráneo respecto a los del sur y viceversa.

Aspectos como la estabilidad o inestabilidad internas, la necesidad integral de abordar transversalmente la democratización en estos países a la par que su despegue económico, las revueltas árabes, el elevado incremento demográfico de los países africanos, las repercusiones a nivel global y regional de los conflictos de Afganistán e Irak, la lucha contra el terrorismo, el reto que supone el escaso desarrollo y la falta de recursos de los Estados centran la agenda de seguridad de los países norteafricanos, sahelianos y subsaharianos, configurándose como un foco de preocupación para la comunidad internacional.

Durante el año 2007 el terrorismo yihadista dio inicio en la región norteafricana del Mediterráneo a un nuevo tipo de atentados que se inscriben dentro del ámbito de influencia del mismo fenómeno a nivel internacional: coches bomba, atentados simultáneos, operaciones suicidas sincronizadas, elección simbólica de fechas y objetivos y un modus operandi cada vez más sofisticado.

El antiguo Grupo Salafista para la Predicación y el Combate, rebautizado como al-Qaeda en el Magreb Islámico recuperó su operatividad y la capacidad de reconstruir redes de militantes yihadistas dispuestos a suicidarse para cometer atentados, a acudir a luchar a 
Irak o Siria y a controlar los volátiles territorios en términos de seguridad de la franja del Sahel, en los que actúa conexionado con el crimen organizado transnacional.

Episodios como el de la ofensiva de la insurgencia yihadista en Mali desde su santuario en el norte del país hacia la capital del mismo, Bamako o, el secuestro masivo llevado a cabo por parte de militantes yihadistas en la planta gasística de In Amenas en Argelia, ambos en enero de 2013, demuestran la capacidad de desestabilización del auge de los grupos yihadistas de la región.

A la inseguridad estructural que plantea el Sahel al haberse constatado su territorio como zona de retaguardia, adiestramiento y campo de batalla de al-Qaeda en el Magreb Islámico en colaboración con las redes del crimen organizado transnacional, se le ha de sumar la inestabilidad que produjo en la región el desencadenamiento de las revueltas árabes a partir de 2011.

Tras el agravamiento de la situación sociopolítica de Irak a finales de 2013, la organización Estado Islámico de Irak y Levante, liderada por Al Bagdadi y que se había escindido poco tiempo antes de alQaeda Central tras desobedecerla, inició una ocupación insurgente y violenta de diversas ciudades iraquíes.

A finales de junio de 2014, Al Bagdadi proclamó un califato panislámico ocupando territorios sirios e iraquíes y comportándose como un Estado, hecho novedoso en sí mismo porque hasta ese momento no se habían producido episodios de conquistas territoriales por parte de otros grupos yihadistas.

El denominado Estado Islámico dio comienzo a la implementación de su agenda internacional tras su expansión por el norte de África en territorio libio tras la fundación en octubre de 2014 en la ciudad oriental de Derna de la primera franquicia de la organización fuera de Siria e Irak (con el conocido como Estado Islámico de Barqa). La profunda situación de caos y deterioro de la seguridad que contempla Libia favorecía la propagación de la violencia yihadista tanto en las fronteras internas del país como por los países de la región. Posteriormente, amplió su presencia en Libia conquistando otros territorios e instaurando los enclaves conocidos como Estado Islámico de Tripolitana y el Estado Islámico de Fezzan.

Túnez, por su parte, presenta un repunte de la actividad yihadista en la región de Kasserine, en la frontera oeste con Argelia y, ha sido testigo de dos atentados de inspiración yihadista de gran envergadura durante el primer semestre de 2015. El atentado cometido en el Mu- 
seo del Bardo de la capital del país el 18 de marzo de 2015 y reivindicado por la organización del Estado Islámico acabó con la vida de 22 turistas. Tres meses más tarde, Túnez fue el escenario de otro ataque yihadista en la ciudad costera de Susa, en la que un individuo vinculado también con el autoproclamado Estado Islámico que previamente había recibido entrenamiento militar en Libia, al igual que los responsables del atentado que tuvo lugar en el Museo del Bardo, asesinó a 38 personas.

Las amenazas a la seguridad e inestabilidad que afectan tanto al propio país, a su vecina Libia como al resto de la región podrían frenar los avances que se han producido en la transición política tunecina. Además, Túnez teme que, debido al elevado número de víctimas extranjeras que se han producido en los atentados que se acaban de señalar, se frene el turismo en el país y, con ello, uno de los pilares económicos fundamentales de su el PIB nacional.

En el avance del autodenominado como Estado Islámico por el norte de África, también se produjo en Egipto el juramento de lealtad de Ansar Beyt al Maqdis así como el del grupo argelino Soldados del Califato.

Con su expansión por el norte de África, el conocido como Estado Islámico adquiere un carácter global aproximándose cada vez más a Europa. En ésta última, la referida organización yihadista ha logrado ya una movilización y captación sin precedentes, afectando a países como Francia, Reino Unido, Alemania, Bélgica, Dinamarca, Países Bajos, Suecia o España.

El riesgo de que los retornados de zonas de conflicto con experiencia en técnicas de combate puedan radicalizar más individuos y cometer atentados se perfila como una de las preocupaciones más graves respecto a la agenda en materia de seguridad de buena parte de la comunidad internacional. Por su parte, la última también encara la posibilidad de que lobos solitarios radicalizados en internet u otros foros también actúen de forma violenta.

Además, el pulso que mantienen entre sí al-Qaeda y el denominado Estado Islámico en su búsqueda de liderar el movimiento de las redes militantes del yihadismo mundial es otro de los elementos que provocan una especial preocupación en la agenda de seguridad internacional debido a las imprevisibles consecuencias que puedan implicar. 


\section{LA SUPERVIVENCIA DE AL-QAEDA A LA DENOMINADA POLÍTICA DE GUERRA GLOBAL CONTRA EL TERROR DE LA ADMINISTRACIÓN DE GEORGE W. BUSH (2001-2008)}

Los combatientes yihadistas que colaboraban con Bin Laden y que fueron expulsados de su santuario afgano por las fuerzas estadounidenses tras los atentados del $11 \mathrm{~S}$ estuvieron a punto de desaparecer debido a la persecución que fueron objeto por parte de las anteriores. Sin embargo, lograron sobrevivir y perpetuarse en suelo paquistaní debido al error histórico cometido por la primera Administración de George W. Bush (2001-2004) de invadir Irak en marzo de 2003 en lugar de centrar todos sus recursos tanto militares, estratégicos como económicos en acabar con al-Qaeda en Pakistán.

La resistencia de al-Qaeda en Pakistán se vio favorecida por la colaboración implícita del gobierno de Islamabad con la red de Bin Laden y los talibanes para recuperar su capacidad de acción y luchar contra la OTAN y el gobierno de Kabul en Afganistán (Ourdan, 2012, 144-145). Pakistán actuó de este modo en su propio territorio contra Estados Unidos dando prioridad a la tolerancia con el movimiento talibán paquistaní frente a su propia desestabilización interna (Setas, 2013, 171-173).

Así pues, la subsistencia de al-Qaeda se hizo factible debido fundamentalmente al recién citado error estratégico de la Administración de George W. Bush y a las maniobras interesadas de Pakistán que se acaban de indicar.

Una de las consecuencias que trajo consigo la declaración de la denominada política de guerra global contra el terror por parte de la primera Administración de George W. Bush (2001-2004) y mantenida durante su segundo mandato presidencial (2005-2008) como respuesta a los atentados del 11S y, los esfuerzos en materia antiterrorista que emprendieron países tanto occidentales como no occidentales, es que el terrorismo yihadista se vio forzado para subsistir a abandonar el modelo jerárquico y rígido por el que venía funcionando la red central de al-Qaeda (Lorenzo-Penalva, 2013,5).

De este modo, la militancia yihadista global optó por un modelo de funcionamiento y organización en red con el fin de facilitar la supervivencia operativa de la misma, centrado en la flexibilidad y capacidad de adaptación de sus miembros, en la horizontalidad del poder en la toma de decisiones, en sus nuevos métodos de comunicación (sobre todo internet) y en sus modos de financiación, basados en la confianza. 
La eliminación de Osama Bin Laden en mayo de 2011 a manos de fuerzas de operaciones especiales estadounidenses en Abbottabad (Pakistán) no derivó, como podría haberse pensado en un principio, en un debilitamiento de la organización al-Qaeda (Mesa, 2014, 2). Es más, podría afirmarse el resurgimiento de la misma con mayor fuerza, ya que el funcionamiento descentralizado e independiente de sus franquicias, células y miembros individuales permite la renovación constante de sus líderes. En este sentido, al-Qaeda Central opera a modo de sociedad terrorista virtual que abastece de ideas e inspiración al terrorismo yihadista.

La adopción y extensión del nuevo modelo de funcionamiento que siguió la organización a través de redes, franquicias y miembros individuales y, que se nutre continuamente de las lecciones aprendidas en las diversas zonas en conflicto, favoreció la optimización de los recursos y las acciones de grupos yihadistas que ya funcionaban en determinadas regiones (como el caso del Grupo Salafista para la Predicación y el Combate reconvertido en al-Qaeda en el Magreb Islámico). Además, contribuyó a agravar la inestabilidad e inseguridad de dichas regiones afectando notablemente, por ende, en sentido negativo a la seguridad internacional.

La supervivencia y perpetuación de al-Qaeda Central y su extensión a través de sus franquicias a nivel internacional demuestra el fracaso de la denominada política de guerra global contra el terror implementada por las dos Administraciones de George W. Bush (2001-2008) tras los ataques en territorio estadounidense del 11S.

En consecuencia, las anteriores obtuvieron el efecto contrario de sus declarados objetivos de expansión de la democracia (entiéndase como democracia liberal) y sus valores en el mundo, ya que la actividad terrorista del salafismo yihadista se incrementó notoriamente. Así se manifiesta el National Intelligence Estimate de 2007 del National Intelligence Council estadounidense, que indicaba que Estados Unidos vivía en una situación de creciente riesgo y amenaza (The USA National Intelligence Council, 2007).

En la misma línea, un informe de 2008 sobre contraterrorismo del Center for Strategic and Budgetary Assessments afirmaba que «Desde 2002-2003, la posición global de Estados Unidos en la guerra global contra el terrorismo se ha debilitado» y, que a pesar de los avances del país en materia de política contraterrorista, los beneficios se habían manifestado "contrarrestados por la transformación de al-Qaeda en un movimiento mundial, por la expansión y la intensificación de la ideología yihadista-salafista, por el resurgimiento de 
la influencia regional iraní y por el aumento del número y de la influencia de los partidos políticos fundamentalistas en todo el mundo (Leffler, 2011, 44-58)».

La guerra contra Afganistán y la invasión a Irak han ocasionado más terrorismo yihadista e inseguridad global, así como un impacto negativo muy relevante en la violencia mundial y el incremento de la expansión geográfica del terrorismo y las organizaciones de inspiración yihadista. Es importante destacar que tras la invasión iraquí por parte de Estados Unidos, se instaló el salafismo yihadista en el país, que no existía antes de la intervención.

En este sentido, se pronunció el Global Terrorism Index 2012 Capturing The Impact of Terrorism from 2002-2011 (Institute for Economics and Peace, 2012, 6-7), indicando que el número de ataques terroristas ascendió incesantemente durante la primera década del siglo XXI.

Irak se confirma como el país que más devastación yihadista e insurgente ha sufrido durante la última década y la inestabilidad y violencia que soporta le ha situado durante el año 2014 como el lugar más violento del planeta. (Institute for Economics and Peace, 2014, 4).

En definitiva, la denominada política de guerra global contra el terror implementada por la Administración de George W. Bush, la guerra contra Afganistán en 2001 y la invasión de Irak en 2003 propiciaron o, al menos, facilitaron las bases para la formación de la nebulosa de al-Qaeda, de la que la actual expansión yihadista en el norte de África es consecuencia: Al-Qaeda en el Magreb Islámico en primera instancia y posteriormente las autoproclamaciones por parte de grupos afines al denominado Estado Islámico de provincias vinculadas al anterior en el norte de África.

\section{LA ESTRUCTURACIÓN GLOBAL DE LA MILITANCIA YIHADISTA. SEPTIEMBRE DE 2015}

Una vez iniciado el segundo semestre de 2015, el terrorismo yihadista se configura como un fenómeno polimorfo que presenta los siguientes niveles interconectados entre sí:

1. Al-Qaeda como estructura terrorista global con matriz en Pakistán, que conforma la red conocida como al-Qaeda Central. Se incluyen en la misma sus franquicias en Yemen (al-Qaeda en la Península Arábiga-AQAP), en Irak (al-Qaeda en Mesopo- 
tamia-AQM) y el norte de África (al-Qaeda en el Magreb Islámico-AQMI) (Reinares, 2013, 1).

2. El conglomerado de organizaciones heterogéneas afines a alQaeda Central o a algunas de sus ramificaciones. Entre las mismas, cabría apuntar al Movimiento por la Unicidad y la Yihad en África Occidental (MUYAO), Al Shabab en Somalia o Harakat al Muyahidin, Therik e Taliban Pakistan (TTP) y Laskhar e Toiba (Let) en el sur asiático, la debilitada Yemaa Islamiya y el grupo de Abu Sayyaf en el sudeste asiático o el Emirato del Cáucaso en territorio ruso, así como otras organizaciones emergentes en Libia, Túnez, Egipto, Siria o los territorios palestinos. Esta serie de entidades asociadas pueden relacionarse directamente con al-Qaeda Central o con algunas de sus franquicias por criterios de proximidad geográfica o por otros tipos de contactos previos (Reinares, 2013, 2-3).

3. En junio de 2014, el Estado Islámico de Irak y Levante dio inicio tras su ocupación insurgente de Mosul en Irak a un nuevo paradigma de yihadismo global, entendido en su acepción belicosa. Tras su autoproclamación como Estado Islámico, la referida organización se hizo con el control de buena parte de territorios tanto sirios como iraquíes desdibujando sus fronteras estatales utilizando unas tácticas militares más propias de un Ejército regular que de un grupo terrorista. Su elocuente uso de las tecnologías y la ocupación de territorio declarando el Califato y comportándose como un Estado le ha permitido llevar a cabo un elevadísimo nivel de reclutamiento de individuos y fidelidad de otros grupos yihadistas a nivel global.

La pugna que mantienen al-Qaeda con sus franquicias regionales y el denominado Estado Islámico por el liderazgo de la yihad mundial puede acarrear imprevisibles consecuencias para la seguridad internacional.

4. Una indeterminada serie de pequeños grupos, células o individuos radicalizados en la ideología salafista yihadista que operan de forma independiente. Los dirigentes tanto de alQaeda con sus franquicias como los del conocido como Estado Islámico vienen realizando reiterados llamamientos para que, aprovechando su residencia en países occidentales, los primeros infrinjan graves daños a quienes ambas organizaciones yihadistas entienden como «infieles» a través de acciones individuales. 
La evolución de salafistas yihadistas hacia las tesis del terrorista sirio de nacionalidad española Mustafá Setmarian Nasar, así como el adiestramiento y radicalización sufrida por parte de muyahidines en zonas de conflicto como Afganistán, Irak, Libia y Siria suponen una de las amenazas más graves a las que se enfrenta la comunidad internacional (Lorenzo-Penalva, 2013, 9).

La peligrosidad de las tesis de Setmarian radica en la apología que realiza sobre un terrorismo universal, descentralizado y al que todo joven musulmán se debe. En esta línea, proclama que cada terrorista puede actuar de forma independiente, sin la pertenencia a células y sin líderes directos.

En su obra maestra «La llamada a la resistencia islámica global», hace un llamamiento a la necesidad de alimentar el frente de la yihad a través de musulmanes radicalizados aislados e independientes, argumentando que la ausencia de organización en sus actividades de inspiración yihadista dificulta las labores contraterroristas de los Estados e incrementa la dificultad de las operaciones de inteligencia de éstos últimos (Lorenzo-Penalva, 2013, 7).

Elementos como la disponibilidad de individuos que hayan combatido la yihad con experiencia en tácticas y uso de armas en zonas de conflicto al regreso a sus países de origen; el honor que el martirio de los militantes yihadistas supone a su familia; la radicalización que se difunde en diversas redes sociales, en algunas mezquitas y en una serie de organizaciones; la propaganda que se realiza de las actividades de inspiración yihadista como acciones dignificantes; el establecimiento de unas bases ideológicas que trasladan a las personas que quieran considerarse buenos musulmanes la necesidad de convertirse en combatientes, etc., pueden favorecer y posibilitar la materialización de las tesis de Setmarian.

La sociedad occidental ha sido testigo de atentados cometidos por lobos solitarios, como los que tuvieron lugar en Francia en marzo de 2012, mayo de 2013 y junio de 2015, en territorio estadounidense en abril de 2013 durante el transcurso del maratón de Boston o en Londres en mayo de 2013 (Lorenzo-Penalva, 2013, 9).

Los miembros y grupos de la yihad global también han incrementado de un modo muy notable su actividad en el ciberespacio hasta el punto de que han asentado el uso de internet para sus actividades de comunicación, reclutamiento, financiación, propaganda, incitación al odio y a la violencia y la guerra psicológica, entre otros aspectos (International Institute for Counter-Terrorism-IDC Herzliya, 2013, 4). 
Desde los últimos años, el movimiento de la yihad global y otras organizaciones de inspiración yihadista vienen utilizando el ciberespacio como campo de batalla para lo que califican como «ciber-yihad» mediante ataques y sabotajes a infraestructuras críticas, el robo virtual de información sensible y el desarrollo de sus propias capacidades defensivas contra ciber-ataques (International Institute for Counter-Terrorism-IDC Herzliya, 2013, 4).

A este resepcto, al-Qaeda en la Península Arábiga (AQAP), se ha consolidado como uno de los grupos salafistas yihadistas más fuertes vinculados a al-Qaeda y como uno de los principales referentes para otros grupos de similar ideología a nivel mundial debido al pragmatismo de sus líderes, que han implementado una atractiva política de comunicación que le ha permitido a la organización reclutar seguidores tanto en el mundo árabe como en Occidente (Alonso, 2014, 1).

Su notoria política de comunicación, que presenta a los combatientes yihadistas como guerreros piadosos y mártires, se ha centrado en unir el descontento popular contra las injusticias sociales cometidas por el régimen yemení, por las estrechas relaciones del anterior con el gobierno estadounidense y por su política de ataques contraterroristas indiscriminados. Además, realiza un llamamiento al regreso del islam puro y a la sharia (Alonso, 2014, 1).

AQAP se distingue por constatarse probablemente como la organización de la red al-Qaeda con mayor proyección internacional y más capacidades para llevar a cabo atentados contra Occidente, ya que su estrategia de comunicación le ha conferido una mayor visibilidad entre individuos familiarizados con las redes sociales, permitiéndole así reclutar a ciudadanos americanos, saudíes o africanos.

AQAP mantiene una firme conexión con otras redes yihadistas y los flujos de combatientes entre Yemen, Irak, Somalia, Afganistán, Siria y Gaza resultan continuos y multidireccionales. Sin embargo, no cuenta con el apoyo que las tribus facilitan a los talibanes en Pakistán y Afganistán debido a que su mensaje globalizador y unificador no cala en la población yemení, familiarizada con las tradiciones tribales.

\section{AL-QAEDA EN EL MAGREB ISLÁMICO}

Al-Qaeda en el Magreb Islámico (AQMI) deriva de la insurgencia islamista que atentó contra Argelia durante los años noventa (Escobar, 2010). Su antecedente directo es el Grupo Salafista para la Predi- 
cación y el Combate (GSPC), creado en 1998 por Hasan Hattab con apoyo de Osama bin Laden. Tras el juramento de obediencia en 2007 del GSPC argelino al anterior, el GSPC comenzó a operar bajo la denominación AQMI.

Los principales objetivos que AQMI señala perseguir son (Ruiz, 2011, 2):

- Reemplazar al Estado en las áreas en las que el último no está presente.

- Provocar la caída de los Gobiernos locales.

- Atacar los intereses occidentales.

- Crear un emirato en el norte de África, que actúe como Estado y transformar el mensaje espiritual del islam en la región. También pretende extender el fundamentalismo islámico a las poblaciones musulmanas de Europa.

La visión fundamentalista del islam en el norte de África es reciente y no ha sido hasta los últimos años la fecha en que se ha extendido la propagación del wahabismo a través de una red de imanes financiada por países del Golfo Pérsico y Pakistán, creando el caldo de cultivo que favorece la actividad yihadista.

El rasgo básico que distingue a AQMI en relación a otras «franquicias» de al-Qaeda lo establece su amplia interacción con la delincuencia organizada. En este sentido, una de las principales fuentes de ingresos de AQMI es el tráfico de drogas, que financia en buena medida las actividades terroristas de la organización en el Sahel y el reclutamiento de nuevos mercenarios entre las redes mafiosas que operan en la región (Alvarado, 2010, 51-74).

Factores como la inestabilidad política, la delicada situación socioeconómica y la corrupción estructural han convertido a la región en una zona franca para todo tipo de tráficos y actividades ilícitas, no únicamente el de la droga, sino también de emigrantes, trata de seres humanos, recursos naturales y desechos tóxicos.

La ineficiencia respecto al control y la escasa cooperación entre los Estados sahelianos han favorecido la actuación de AQMI como una red mafiosa y criminal más que interviene en una variada gama de tráficos y actividades ilícitas, en las que ha encontrado recursos para la financiación de sus actividades desestabilizadoras y terroristas. 
Los secuestros, especialmente de ciudadanos occidentales, se han convertido para AQMI en otra de las actividades que financian sus operaciones criminales y de promoción de su mensaje. El 16 de enero de 2013 tuvo lugar el secuestro posiblemente de mayor envergadura en la historia de Argelia cuando terroristas pertenecientes a la katiba fundada a finales de 2012 por el argelino Mojtar Belmojtar secuestraron a cerca de 800 personas en el complejo gasístico de Tiguentourine en In Amenas.

El primer ministro argelino, Abdelmalek Sellal, indicó que el referido ataque terrorista no pretendía en origen tomar la planta gasística, sino secuestrar a los empleados extranjeros que cada miércoles realizaban en autobús el trayecto de 50 kilómetros que separan Tiguentourine y el aeropuerto de la ciudad de Amenas para viajar a Europa. Sin embargo, al ser repelidos por la seguridad que custodiaba el autocar, los terroristas decidieron atacar la planta gasística Tiguentourine. Tras la intervención de las fuerzas especiales del Ejército argelino, el secuestro del complejo finalizó con un resultado de 38 civiles de 8 nacionalidades distintas y 29 terroristas fallecidos.

Los efectos de la guerra de Libia y de las revueltas árabes produjeron una expansión de AQMI por el norte desértico de Mali, Mauritania y Níger. La porosidad de las fronteras estatales de la región del Sahel favorecieron así el trasvase de combatientes yihadistas en conexión con el crimen organizado a Libia tras la desestabilización total que sufrió el país tras las revueltas árabes, profundizando aún más la situación de caos que vive el anterior.

En marzo de 2012 se produjo la fractura total de Mali cuando grupos rebeldes tuareg declararon su independencia bajo la denominación del Estado de Azawad. Al año siguiente, en enero de 2013, se hizo precisa la operación militar francesa Serval para detener el avance y despliegue de los yihadistas desde el norte de Mali hasta la capital, Bamako. Tras el fin de Serval en julio de 2014, Francia amplió su presencia en la región con la Operación Barkhane con el objeto de mantener en Mali la presión sobre los grupos yihadistas.

\section{LA FRANJA DEL SAHEL}

El Sahel se configura como una vasta y volátil región natural en términos securitarios, que conexiona África Occidental con el cuerno de África, dos de las regiones más inestables políticamente del continente. La franja también une el norte de África con el África Subsaha- 
riana y, buena parte de sus problemas y retos se encuentran fuertemente conectados con países como Libia, Argelia y Marruecos (Echeverría, 2001, 213-214).

La región se caracteriza además de por la criminalidad, el terrorismo y la aridez de sus territorios, por la primacía de las estructuras tribales sobre la de los propios Estados. La dificultad que presentan los últimos para controlar y ejecutar el monopolio de la violencia en el Sahel ha favorecido notablemente la actividad en la región de alQaeda en el Magreb Islámico. A su vez, el Sahel multiplica su grado de inseguridad estructural al haberse constatado como zona de redespliegue y campo de batalla del terrorismo yihadista.

La franja del Sahel ofrece unas condiciones singulares que favorecen la actividad terrorista en la misma (Ruiz, 2011, 2):

- La pobreza endémica de su población, que muestra uno de los índices de desarrollo humano más bajos del planeta.

- El desagrado de las poblaciones de zonas remotas con la insuficiencia o ausencia de servicios ofrecidos por los Gobiernos estatales.

- La propagación de una interpretación fundamentalista del islam. La presencia de combatientes extranjeros procedentes de Irak o Pakistán, así como nuevos predicadores financiados desde Arabia Saudí, originó la extensión de la corriente wahabí.

- La existencia de enormes fronteras, artificialmente trazadas durante la época colonial y que los Estados no son capaces de controlar.

- El impacto de conflictos externos a la región, como la invasión estadounidense a Irak en 2003.

- La ausencia de una democracia real, la corrupción generalizada y la opresión a la población.

- El vínculo entre terrorismo y crimen organizado en actividades como el contrabando, el blanqueo de dinero y los secuestros.

- La lucha por el control de los recursos naturales estratégicos, como el petróleo o el uranio, que reavivó conflictos latentes (Conde, 2011, 3-4). 
- La expansión regional de los conflictos, promovidos en muchos casos por la injerencia de otros Estados en los asuntos internos de los países fronterizos.

- La fragilidad de los Estados, desgastados por las luchas internas por el control del poder.

- La limitada capacidad de las fuerzas armadas de los Estados sahelianos para proporcionar seguridad y controlar todo su territorio, asunto especialmente complejo en una zona de escasa tradición en el poder centralizado, donde habitualmente los gobiernos deben apoyarse en milicias locales o fuerzas internacionales para asegurar el control de una zona.

- Las fuerzas gubernamentales de los países sahelianos se significan por su falta de profesionalidad, mala equipación, por sus estructuras de mando altamente personalizadas, su marcado carácter étnico, desmotivación y un elevado nivel de deserciones. Con asiduidad, llevan a cabo actividades ilícitas paralelas fomentadas en buena medida por el impago de los salarios.

- La militarización de la población y la aparición de multitud de grupos rebeldes. Los Estados sahelianos carecen de unos oportunos programas de desarme, desmovilización y reintegración, por lo que la pertenencia a una milicia es la mejor forma de subsistencia para muchos antiguos combatientes.

— El fácil acceso de la población a las armas pequeñas y ligeras y su proliferación facilita la permanencia de los conflictos en la zona.

- Las economías de guerra y la actuación de los señores de la guerra, que nutren situaciones de conflicto en beneficio propio, motivando además un incremento de actividades ilegales llevadas a cabo por grupos militares y bandas organizadas.

La guerra inacabada que está teniendo lugar en Mali contra el terrorismo yihadista y la rebelión de las milicias tuaregs, la caída del gobierno de Burkina Faso, la guerra civil en la República Centroafricana, el conflicto de Sudán del Sur o las violentas acciones de Boko Haram en el norte de Nigeria y Camerún, entre otros elementos, se deben precisamente a los factores estructurales que se acaban de señalar y que facilitaron el establecimiento de las circunstancias que llevaron al caos en Libia y a la proliferación de armas y combatientes por la región del Sahel (Argumosa, 2015, 2). 


\section{AL-QAEDA TRAS LAS REVUELTAS ÁRABES Y LA ECLOSIÓN DEL ESTADO ISLÁMICO DE IRAK Y LEVANTE COMO PRECURSOR DE LA ORGANIZACIÓN DEL ESTADO ISLÁMICO}

Desde el inicio de las revueltas árabes a partir de 2011 en diversos países del norte de África y el Próximo y Medio Oriente, tanto alQaeda Central como sus franquicias regionales han buscado beneficiarse de las oportunidades que pudiesen surgir para satisfacer sus intereses propagandísticos, incrementar su capacidad de reclutamiento de voluntarios, fomentar el impulso de acciones violentas y ampliar su nivel de financiación mediante su interconexión con el crimen organizado trasnacional y la ejecución de otras actividades delictivas.

Siria se convirtió en el principal destino de los combatientes yihadistas extranjeros y en el nuevo centro de poder mundial del yihadismo, desestabilizando notoriamente la región y centrando el foco de preocupación internacional en términos de campo de batalla yihadista globalizado más alarmante que los casos previos de Afganistán en los años ochenta, Chechenia y los Balcanes en los años noventa o Irak en la década pasada (Echeverria, 2014, 1).

El profesor Manuel R. Torres apunta en cuanto a la predilección de Siria para combatir la yihad por parte de elementos radicalizados que la disponibilidad de vuelos de bajo coste a Turquía y la notable permisibilidad que presentaron las autoridades turcas para cruzar las fronteras sirias situaron al conflicto sirio como el gran foco de atracción del salafismo yihadista internacional (Torres, 2013).

La guerra que se originó en Siria en marzo de 2011 tras el estallido las revueltas árabes posibilitó el establecimiento en el país de grupos de combatientes yihadistas particularmente violentos sobre el terreno (Echeverria, 2014, 1) operando con un mismo fin, esto es, el derrocamiento del presidente sirio al Asad para implantar un Estado islámico difusor de su ideología salafiya yihadiya a través de la aplicación literal del texto religioso sin opción a interpretación y, posteriormente extender la lectura rigorista de la ley islámica en un emirato abarcando el territorio de Irak, Siria y el Líbano (Mesa, 2014, 1-8).

Dentro del terrorismo yihadista que ejerce su actividad en territorio sirio, se produjeron diversas escisiones compitiendo violentamente entre sí por el liderazgo en la lucha por el poder. El líder de alQaeda Central, Al Zawahiri, siempre ha abogado por que sea el Frente al-Nusra la organización que centralice los esfuerzos de combate yihadista contra el régimen sirio de al Asad y sus apoyos consi- 
derados como "desviados del islam» (Hizbollah o Partido de Dios libanés, los Pasdarán o Guardia Revolucionaria iraní y los grupos chiíes iraquíes como el Ejército del Mahdi de Muqtada al Sadr) y, por su parte, que el Estado Islámico de Irak (sin el apellido Siria o Levante) fuera la organización que fijara su campo de acción en Irak (Echeverría, 2014, 1).

El Estado Islámico de Irak y Levante (EIIL) nunca ha rendido pleitesía a al-Qaeda Central y le disputa el liderazgo del movimiento del yihadismo global al propio Al Zawahiri, a quien califica de apóstata. El primero se configuró como la organización yihadista más potente y letal durante el año 2014 (Echeverría, 2014, 5) tras la declaración del Califato por parte de su líder, Abu Bakr Al Baghdadi, ocupando tierras sirias e iraquíes a finales de junio de 2014.

El EIIL hunde sus raíces en Irak en el año 2004 bajo el nombre de al-Qaeda en Irak y el liderazgo del jordano Al Zarqawi, quien combatió junto a Osama bin Laden en el Afganistán ocupado por los soviéticos. Al Zarqawi fue eliminado en territorio iraquí en 2006 como consecuencia de un bombardeo selectivo estadounidense (Núñez, 2014, 110).

Tal como afirma Loretta Napoleoni, Al Zarqawi era prácticamente un desconocido en el mundo de la militancia del yihadismo global hasta que el entonces Secretario de Estado en la primera Administración de George W. Bush (2001-2004) Colin Powell le señaló como el representante de al-Qaeda en Irak, momento a partir del cual el referido grupo comenzó a recibir recursos económicos por parte de patrocinadores (Napoleoni, 2015, 72).

La Administración de George W. Bush elevó la figura de Al Zarqawi a la categoría de mito tras su imperiosa necesidad de poner más de una cara a la actividad violenta de al-Qaeda tras el 11S con el objeto de justificar la invasión a Irak que empezaba a materializarse (Napoleoni, 2015, 71). A este respecto, los servicios secretos kurdos habían interpretado sin pruebas fehacientes la fusión de Jund al Islam (varios de cuyos miembros habían coincidido con Al Zarqawi en una cárcel jordana) con Ansar Al Islam como una prueba de que Al Zarqawi actuaba como emisario entre ambos grupos.

Desde el 11S hasta la invasión estadounidense a Irak el 20 de marzo de 2003, Al Zarqawi había sido uno de los elementos alegados como la supuesta vinculación existente entre Sadam Hussein y alQaeda que la Administración de George W. Bush precisaba para intentar convencer a la comunidad internacional de la necesidad de derrocar al dictador iraquí (Napoleoni, 2015, 72). 
En sus inicios, al-Qaeda en Irak contaba con capacidad para desarrollar su actividad terrorista en territorio tanto iraquí como jordano. En aquel momento, se dedicaba a cometer atentados puntuales contra chiíes en general y personas o bienes vinculados a los regímenes políticos que buscaba derrocar debido a que no disponía de capacidades que le permitiesen plantearse controlar un territorio propio en la línea de sus aspiraciones de instaurar un emirato (Núñez, 2014, 111).

Tras el Surge estadounidense iniciado en 2007 con la colaboración de los Consejos del Despertar suníes, al-Qaeda en Irak se mantuvo bajo mínimos hasta su vuelta a escena en 2013 en Siria, influida y favorecida posiblemente por el interés saudí de apoyar económicamente a grupos suníes para hacer frente al régimen sirio y frenar así el incremento de la influencia iraní en la región.

La nueva estrategia que desarrolló en Irak la Administración de George W. Bush The New Way Forward (The Surge) fue la respuesta de Estados Unidos ante el continuo incremento de insurgencia, terrorismo, sectarismo y delincuencia con un notable aumento del número de fuerzas desplegadas en el país, sobre todo en Bagdad y la provincia de al-Anbar. Ni el ejército norteamericano ni el Gobierno iraquí eran capaces de controlar los niveles de violencia que asolaban el país (Arteaga y García, 2008, 1-8).

The Surge redujo significativamente los indicadores de violencia, relegando a los combatientes afines a al-Qaeda a la provincia de Diyala y al «triángulo de la muerte». A este resultado también contribuyeron factores exógenos a The Surge, como la disminución del número de combatientes yihadistas extranjeros procedentes de Siria debido al propósito sirio de recomponer sus relaciones con Estados Unidos y al continuo desplazamiento de civiles voluntario o forzado por la limpieza étnica desde las zonas mixtas a las seguras (Arteaga y García, 2008, 1-8).

Al-Qaeda en Irak reapareció en el escenario de conflicto bélico sirio en 2013 bajo la denominación de Estado Islámico de Irak y Levante desoyendo las instrucciones dispuestas por Ayman al Zawahiri, sustituto de bin Laden al frente de al-Qaeda (Núñez, 2014, 111). El nuevo número uno de la organización, Al Bagdadi, desobedeció las órdenes de $\mathrm{Al}$ Zawahiri, en el sentido de que exigía que abandonara el territorio sirio a favor de la rama local de al-Qaeda, el Frente al-Nusra.

El Estado Islámico de Irak y Levante amplió su campo de acción tanto a las provincias sirias del este como a Alepo y adoptó en sus operaciones una elevada disciplina y capacidad operativa, incluyendo en sus filas combatientes de diversos orígenes (Núñez, 2014, 111). 
La derrota del EIIL en sus feudos sirios a manos del Frente Islámico al-Nusra llevó al líder de al-Qaeda, Ayman al Zawahiri en noviembre de 2013 a considerar al segundo como la única filial de al-Qaeda en Siria y a anular la actuación del primero en el país. Según al Zawahiri, el EIIL debería llevar a cabo a partir de ese momento su actividad terrorista únicamente en territorio iraquí (Arteaga, 2014, 9).

A finales de 2013, la detención de Ahmed al Aluani, diputado crítico al ex primer ministro iraquí Nuri al-Maliki y afín a las protestas suníes produjo una serie de manifestaciones masivas de miles de suníes en diversas ciudades de Irak para exigir reformas en el proceso político y exigir la liberación de los detenidos.

Estas protestas derivaron en movilizaciones permanentes en las capitales de las provincias de mayoría suní, incluida Anbar. La tensión derivó en un estallido de violencia por parte del EIIL y grupos sunitas locales muy radicalizados contra las fuerzas de seguridad en Ramadi en primer lugar y extendiéndose posteriormente a Faluya y a Bagdad (Arteaga, 2014, 10).

Por vez primera en varios años, ni las fuerzas de seguridad ni las milicias Sahwa contrarias a los grupos insurgentes suníes pudieron hacer frente al avance de la violencia yihadista. Con la toma de Faluya en Irak y la ocupación de Raqqa en Siria, el EIIL hizo patente la recuperación de la capacidad de lucha de las redes yihadistas y el éxito de su nueva estrategia, consistente en aprovechar el caos regional para ocupar territorios y hacerse con el poder en los mismos.

El gobierno del ex primer ministro iraquí Nuri al-Maliki fue incapaz de controlar su territorio a través de las fuerzas de seguridad de Irak, formadas por combatientes suníes, combatientes (peshmerga) kurdos y combatientes chiíes.

La toma de Mosul a mediados de junio de 2014 por parte del EIIL tras la derrota del Ejército iraquí se erigió como un hito de primer orden en el cada vez más profundo conflicto entre suníes y chiíes al que asiste Oriente Medio. La ocupación de la ciudad se debió en buena medida a los errores cometidos por el Ejército iraquí al concentrar éste último buena parte de sus fuerzas en los principales núcleos insurgentes en la provincia de Anbar, sobre todo en la ciudad de Faluya, reduciendo así considerablemente sus tropas en la segunda ciudad del país (Calvo, 2014). A estos hechos se unieron las ocupaciones de otras ciudades como Faluya, Ramadi y Samarra (Arteaga, 2014, 1). 
Naciones Unidas elevó en agosto de 2014 la crisis humanitaria de Irak al nivel 3 de emergencia, el más alto para este tipo de crisis. Tras la oleada de ataques y violencia iniciada por el EIIL en junio de 2014, Irak cuenta con una de las poblaciones de desplazados más numerosas del mundo (ONU, 2014).

La complicada situación que soporta Irak y que posibilitó un rápido avance del EIIL en las provincias suníes del norte deriva en buena medida de la incompetencia profesional de los mandos del Ejército iraquí (Fuente, 2014, 7); de la desmoralización de las fuerzas de seguridad iraquíes (Arteaga, 2014, 2), fundamentalmente chiíes que defienden una tierra que no entienden como propia y conscientes de que se fijan como el objetivo preferente de la insurgencia suní; de la hostilidad que sufren por parte de la población dependiendo de las zonas de afinidad étnica en las que se encuentren; del continuo incremento de la polarización suní-chií y una notoria desafección de buena parte de la población suní hacia las autoridades gubernamentales de Irak y, de la problemática que supone combatir a la insurgencia en las ciudades.

Los aspectos anteriormente señalados han producido un constante aumento del número de deserciones y de la incorporación a las filas de la insurgencia suní por parte de fuerzas de seguridad iraquíes.

Los combatientes del EIIL, entre cuyas filas figuran gran cantidad de voluntarios extranjeros, ofrecieron una moral de combate muy superior y una capacidad operativa mucho más eficaz que las Fuerzas Armadas iraquíes que, tal como se acaba de mencionar, presentaron una débil oposición (Fuente, 2014, 7). Los primeros actúan muy motivados por una ideología visionaria, que favorece que asuman situaciones de riesgo que otros grupos no aceptarían (Núñez, 2014, 112).

El EIIL se comporta como un grupo híbrido que emplea tanto métodos terroristas como tácticas militares avanzadas (I. Fuente, 2014, 7), entendiéndose así que una fuerza de poco más de 1.000 combatientes del EIIL con armas y vehículos ligeros consiguiera hacer huir a 30.000 soldados del Ejército regular iraquí.

\section{CALIFATO}

El EIIL declaró el 29 de junio del año 2014 un Califato panislámico bajo el mando político y religioso de su líder, Al Bagdadi, en un territorio sin fronteras abarcando el este de Siria y un extenso territorio del norte y oeste de Irak y habitado aproximadamente por unos 
ocho millones de personas. Al Bagdadi se autoproclamó como máxima autoridad espiritual y política de los musulmanes, a quienes exigió lealtad, bajo la formulación doctrinal clásica del islam suní y una supuesta suprema legitimidad derivada de la familia y de la tribu del Profeta, (Rupérez, 2014).

El a partir de ese momento autodenominado como Estado Islámico, se centró en la construcción de un santuario bajo su ideología salafista en Mesopotamia regido por la sharia en su versión más rigorista y en la idea de proveerse de un Estado propio conforme a los usos y costumbres del siglo VII. Asimismo, entendió que debía actuar como un Estado y emprendió una estrategia con objetivos concretos como dar cobertura y asistencia social a la población que vive en los territorios ocupados, impulsar la actividad económica y la difusión mediática (Barrancos, 2014, 4) comportándose como una auténtica administración con gestión profesional.

La ocupación de territorio le permite a la organización del Estado Islámico contar con un amplio espacio en el que entrenarse y ganar experiencia tanto para el campo de batalla como para extender a otros lugares su singular visión y actividad (Núñez, 2014, 112).

En su modus operandi, compagina la extrema violencia y brutalidad con métodos tan extremos o más que los utilizados por al-Qaeda (pero no por ética, sino por oportunismo en el sentido de querer ganarse a las poblaciones musulmanas y mejorar su imagen global) con el uso audaz de las tecnologías de la información (Ruiz, 2014, 54).

La organización publicita su mensaje en las redes sociales y en medios de comunicación a través de la propaganda que realizan sus simpatizantes y militantes, muchos de los cuales se dedicaban con anterioridad al diseño gráfico y a la dirección cinematográfica de manera profesional (Barrancos, 2014, 7).

A través de la difusión de su propaganda online, la organización pretende atemorizar a los soldados de los Ejércitos de Irak y Siria; buscar apoyo a nivel mundial; captar a nuevos militantes para que se unan a su causa; radicalizar a individuos en los países occidentales y, establecer nuevas alianzas con otras organizaciones terroristas (Barrancos, 2014, 8).

La extrema radicalidad y violencia de los combatientes del conocido como Estado Islámico puede indicar que se encuadran en los sectores más radicalizados de la militancia yihadista internacional y, por lo tanto, de los individuos que más peligro pueden suponer para la seguridad internacional (Berenguer, 2014, 14). 
El denominado Estado Islámico se ha convertido en la organización yihadista mejor financiada del mundo (Laborie, 2014). La fuente principal de financiación del primero procede de la venta de hidrocarburos en el mercado negro. En este sentido, controla una serie de campos de petróleo y gas y refinerías en los territorios que ha ocupado en Siria e Irak.

Además, el autoproclamado Estado Islámico instauró un sistema que alterna una forma islámica de tributación con actividades características del crimen organizado como son las extorsiones, la intimidación, los robos, los saqueos y contrabando de mercancías y personas. Asimismo, el secuestro se constata como otro importante fuente de negocio para la organización (Laborie, 2014).

La coalición internacional liderada por Estados Unidos y formada tras el Acuerdo de Paris con fecha de 15 de septiembre de 2014 lucha contra las posiciones de la organización del Estado Islámico. En el mejor de los casos, podrá contener la expansión del denominado Estado Islámico, pero no a corto plazo (Arteaga, 2014, 1). Tampoco existen garantías de que la coalición pueda acabar con el anterior. La amenaza del conocido como Estado Islámico es global y afecta a la comunidad internacional tras la internacionalización de su agenda con su propagación por el norte de África y el África Subsahariana.

\section{LA EXTENSIÓN DE LA ORGANIZACIÓN DEL ESTADO ISLÁMICO POR EL NORTE DE ÁFRICA}

La organización del Estado Islámico optó desde su autoproclamación a finales de junio de 2014 por sostener y ampliar los territorios que ocupa en Siria e Irak. Pero también, por expandir la presencia territorial no contigua de su Califato donde surgiese la oportunidad, aceptando los juramentos de lealtad de las organizaciones yihadistas que actúan en zonas del norte de África (también del África Subsahariana). De este modo, asentaba su estrategia de búsqueda del liderazgo del movimiento de la yihad global, en evidente pugna con al-Qaeda y sus franquicias regionales, buscando de paso el efecto llamada de los combatientes yihadistas de la región para unirse a sus filas.

El conocido como Estado Islámico supo aprovechar la situación de caos regional para sentar las bases de su expansión en el norte de África, debido a que la situación de inestabilidad de Estados fallidos o en vías de transición política junto a la pobreza generalizada de la 
población y su falta de perspectivas de futuro crea el caldo de cultivo de la generación de más violencia y extremismos (Reinares, 2015).

Su establecimiento en el norte de África le acerca además al sur de Europa y, con ello, a los Estados europeos que han sustentado a la coalición internacional liderada por Estados Unidos para combatir la presencia de la organización del Estado Islámico en Siria e Irak. Por ello, la proximidad geográfica del denominado Estado Islámico supone en sí misma una grave amenaza estratégica para Europa, ya que el líder del conocido como Estado Islámico amenazó directamente a los países que forman parte de la coalición internacional, tanto a los que participan directamente en los bombardeos como a los que desarrollan tareas logísticas.

Desde el final del régimen de Gadafi en Libia en 2011 a partir del proceso desencadenado por las revueltas árabes, se crearon las bases de cultivo idóneas para la expansión de la organización del Estado debido a la situación de guerra civil, de Estado fallido y violencia generalizada en la que se encontraba el país. La fundación en la ciudad oriental de Derna de la primera ocupación territorial del denominado Estado Islámico fuera de las fronteras de Siria e Irak en octubre de 2014 constató el interés de la organización yihadista por ampliar su agenda internacional. El Consejo Consultivo de la Juventud Islámica declaró que tanto Derna como su entorno se unían al autoproclamado Califato del Estado Islámico como provincia de Wilayat Barqa, correspondiente a parte de la Cirenaica (Reinares, 2015).

Poco después, en noviembre de 2014, los Muyahidin de Libia anunciaron su juramento de obediencia al conocido como Estado Islámico y el establecimiento de una demarcación del Califato en territorio libio más extensa y formada por tres provincias. Así pues, aparte de la ya mencionada de Barqa, los Muyahidin de Libia autoproclamaron la fundación de otras dos provincias más, una en Fezzan y otra entorno a Trípoli. Al tiempo, los militantes libios de la organización del Estado Islámico se desplazaron hacia el oeste y comenzaron a operar en Bengasi, Naufiliya y Sirte (Reinares, 2015).

Aunque buena parte de los combatientes del denominado Estado Islámico que ejercen su actividad yihadista en Libia son nacionales del país, es significativa la cantidad de extranjeros originarios de Estados de la región que han viajado a territorio libio, en parte debido a la llamada efectuada sobre todo en las redes sociales a los jóvenes musulmanes de origen magrebí o europeo para trasladarse a la zona del mismo modo que hasta el momento se les exhortaba a viajar a Siria e Irak. La porosidad que caracteriza a las fronteras libias favore- 
ce notablemente el flujo de combatientes yihadistas, armas y otros tráficos ilícitos desde otros países de la región hacia Libia.

El conocido como Estado Islámico publicó en febrero de 2015 el dramático vídeo «Un mensaje firmado con sangre», en el que miembros de la organización decapitaban a 21 cristianos coptos secuestrados en Sirte, la mayoría egipcios. El mensaje se dirigía a «la nación de la Cruz» afirmando que el autoproclamado Estado Islámico se encontraba "al sur de Roma», con claras referencias a los cristianos de Europa. El número 4 de Dabiq (la publicación de referencia que edita el autodenominado Estado Islámico y que difunde en internet) recogía en su portada el estandarte negro de la organización ondeando sobre la plaza de San Pedro en el Vaticano.

Como apunta el profesor Arteaga, existe el riesgo de que los militantes yihadistas del autoproclamado Estado Islámico, ya sean árabes, norteafricanos o europeos, decidan viajar a Libia para ampliar el Califato que hayan establecido en el Levante o intentarlo de nuevo si fracasan en Siria e Irak (Arteaga, 2015).

Túnez, que se encuentra inmerso en una transición política que adolece de debilidades estructurales e institucionales, afronta los riesgos que supone para su estabilidad estatal su cercanía geográfica a Libia, que presenta como se acaba de indicar profundos problemas en lo que a su seguridad se refiere.

Aunque cuenta con una población de poco más de diez millones de habitantes, Túnez se evidencia como el país con mayor número de nacionales que han viajado al conflicto abierto en Irak y Siria (Altuna, 2015, 18). El gobierno tunecino deberá gestionar el hipotético regreso a su país de origen de este elevado número de militantes yihadistas con experiencia en campo de batalla, con todos los riesgos que implica tanto para su seguridad nacional o al nivel regional o internacional.

La región tunecina de Kasserine, limítrofe con Argelia, es testigo de hostilidades entre fuerzas armadas tunecinas y grupos yihadistas compuestos por nativos de la zona pero también por individuos originarios del norte de África, el Sahel y el África Subsahariana simpatizantes del autoproclamado Estado Islámico (Martín, 2015, 109).

Dos atentados de inspiración yihadista constataron durante el primer semestre de 2015 la amenaza que supone para Túnez este fenómeno violento. En marzo del presente año, un ataque de inspiración salafista yihadista perpetrado en el Museo del Bardo de la capital tunecina por un grupo afín a al-Qaeda en el Magreb Islámico acabó con 
la vida de 22 turistas. Otro atentado de similares características sacudió el país el 26 de junio pasado, fecha en la que también se produjeron otros tres episodios yihadistas en Francia, Kuwait y Somalia respectivamente (Sánchez, 2015,50-51). Susa, una ciudad de la costa tunecina, fue el escenario del asesinato de 38 turistas de diversas nacionalidades por parte de un individuo vinculado con la organización del Estado Islámico. A este respecto, el turismo se configura como uno de los objetivos preferentes de la militancia yihadista en el país debido a la trascendencia del sector para la economía nacional.

La inestabilidad en el norte de África en lo que a la amenaza yihadista se refiere, se agudizó con la presencia de los Soldados del Califato (una escisión de al-Qaeda en el Magreb Islámico) en Argelia y con el establecimiento de Ansar Bayt al-Maqdis en Egipto.

En Argelia, cuna de al-Qaeda en el Magreb Islámico, el grupo Soldados del Califato o Jund al-Klalifa declaró su lealtad al denominado Estado Islámico en septiembre de 2014 acusando a los líderes de alQaeda de desviarse de los objetivos a seguir. Días después de su adhesión al conocido como Estado Islámico, la organización Soldados del Califato decapitó al rehén de nacionalidad francesa Hervé Goundel a modo de represalia por la intervención de Francia en la coalición internacional gestada en septiembre de 2014 para luchar contra el autoproclamado Estado Islámico (Morales, 2015, 19).

Por su parte, en Egipto la amenaza de Ansar Bayt al-Maqdis se circunscribe en el desierto del Sinaí, representando una amenaza directa a Israel. Desde el inicio de su propio episodio de revuelta árabe, la zona del Sinaí se ha constituido para las autoridades egipcias como un foco permanente de preocupación respecto a su seguridad.

Ansar Bayt al-Maqdis juró lealtad al denominado Estado Islámico el pasado 10 de noviembre de 2014 y, a partir de ese momento, autoproclamó el Wilayat Sinai, la provincia del Sinaí en territorio egipcio en la órbita del conocido como Estado Islámico (Morales, 2015, 16-18).

En lo referente a Marruecos, sus autoridades han desarticulado en los últimos meses varias células yihadistas en el país vinculadas con el denominado Estado Islámico. A este respecto, en marzo de 2015 una operación antiyihadista desarrollada en nueve ciudades por las Fuerzas y Cuerpos de Seguridad del Estado marroquíes desmanteló una célula que ya albergaba información avanzada para ejecutar la implementación de varios atentados. Los individuos que formaban parte de la referida red, conocida como Estado Islámico en Magreb al Aqsa-Descendientes de Yusef ben Tachfine, habían jurado lealtad al 
líder del autodenominado Estado Islámico y disponían del material preciso para cometer ataques (Morales, 2015, 18).

En cuanto al África Subsahariana, Nigeria afronta la violencia descontrolada de Boko Haram, milicia que juró lealtad en marzo de 2015 al líder del conocido como Estado Islámico buscando propaganda y legitimidad para sus acciones terroristas. Bajo el liderazgo de Abubacar Shekau, la organización se ha reforzado debido a su capacidad de captación, reclutamiento y radicalización de individuos. Desde julio de 2014, la estrategia de Boko Haram se centra en la ocupación fáctica de territorios y en los ataques frontales a fuerzas militares, propagando sus acciones terroristas y militares a las fronteras nigerianas y operando también en Camerún, Níger y Chad (Díez, 2015, 14-16).

El vínculo de los grupos extremistas africanos con sus correligionarios de la organización del Estado Islámico en Oriente Medio se basa fundamentalmente en la lealtad, interés y compromiso ideológico. Comparten el objetivo maximalista de implantar la sharia o ley islámica, pero no así el de jerarquía ni dependencia puesto que el yihadismo global no presenta una estructura centralizada (Díez, 2015, 4). Así pues, la aparición del denominado Estado Islámico en diferentes áreas y regiones le dispensa flexibilidad en las potenciales acciones a llevar a cabo (Sánchez, 2015, 10).

A pesar de que el desafío del terrorismo yihadista sigue siendo significativamente superior en Oriente Medio, África es la región del mundo en la que ha proliferado a mayor velocidad el salafismo yihadista (Díez, 2015, 3) y la mayor proveedora mundial de combatientes yihadistas que viajan a Siria y a Irak para luchar.

\section{CONCLUSIONES}

La arena geopolítica mundial ha observado en la última década un estallido de inestabilidad global con la aparición de riesgos asimétricos y difusos de actores cada vez más incontrolables por los Estados, como las redes del terrorismo yihadista y el crimen organizado trasnacional, con imprevisibles consecuencias en el ámbito de la seguridad internacional.

La denominada política de guerra global contra el terror iniciada por la primera Administración de George W. Bush en 2001 tras los atentados que tuvieron lugar el 11S en territorio estadounidense y 
que mantuvo hasta el final de su segundo mandato presidencial a finales de 2008, produjo un retroceso democrático en el mundo, ya que además de actuar unilateralmente, ambas Administraciones vulneraron sistemáticamente los derechos humanos con la implementación de unas políticas que supuestamente iban a expandir los valores democráticos (occidentales) a nivel global, tal como ocurrió por ejemplo con la Ley de Comisiones Militares.

De este modo, no avanzó en la promoción de la democracia en el Próximo y Medio Oriente, a pesar de que ésta era una de sus máximas principales en cuanto a la implementación de su argumentada política de guerra global contra el terror. En este sentido, no incrementó la seguridad internacional -entendida como la estabilidad social que permita mantener el statu quo actual de la sociedad internacionalsino que más bien la ha deteriorado, propiciando el surgimiento de numerosos conflictos a lo largo y ancho del mundo musulmán y árabe. $\mathrm{O}$, al menos, proporcionando una de las justificaciones o excusas para su eclosión.

Otro de los efectos que produjo, además de la inestabilidad en el Próximo y Medio Oriente, fue la exportación del terrorismo yihadista a otras muchas partes del mundo en las que su presencia no existía, no era relevante o estaba latente, como en el norte de África.

La presencia de los grupos de militancia yihadista que operan en el norte de África en connivencia con el crimen organizado se perfila como una de las principales preocupaciones en materia de seguridad para la comunidad internacional y, sobre todo, para la Unión Europea debido a su proximidad geográfica con la región. El terrorismo yihadista amenaza así en África con minar y debilitar los avances logrados en el ámbito económico, político, social y de seguridad en las áreas en las que actúan tanto los grupos conexionados con la organización del Estado Islámico como los vinculados a las franquicias de al-Qaeda.

El antiguo Grupo Salafista para la Predicación y el Combate, rebautizado como al- Qaeda en el Magreb Islámico y constituyéndose como una franquicia asociada a al-Qaeda Central, recuperó a partir de 2007 su operatividad y capacidad de implementar su actividad yihadista y delictiva en conexión con el crimen organizado trasnacional que opera tanto en la franja del Sahel como en el conjunto de la región.

Episodios como la ofensiva de la insurgencia yihadista en Mali que tuvo lugar en enero de 2013 desde su santuario en el norte del país hacia la capital del mismo, Bamako o, el secuestro masivo lleva- 
do a cabo por parte de militantes yihadistas en la planta gasística de In Amenas en Argelia también en enero de 2013 demuestran la capacidad de desestabilización del auge de AQMI en la región.

La implosión del conocido como Estado Islámico de Irak y Levante como grupo desvinculado a al-Qaeda Central y la autoproclamación del califato a finales de junio de 2014 por parte de su líder en un territorio sin fronteras que ocupó militarmente entre Siria e Irak sometiendo brutalmente a su población y enemigos dio inicio a una nueva etapa dentro del yihadismo global.

La extensión de provincias en el norte de África del autodenominado califato en territorio no contiguo al de las tierras que ocupa en Siria e Irak manifiesta la voluntad del denominado Estado Islámico de ampliar su agenda y presencia internacional, que constituye en sí misma una gravísima amenaza para la seguridad internacional.

En la actualidad, al-Qaeda junto a sus franquicias regionales y la organización del Estado Islámico, enfrentadas entre sí, compiten por el liderazgo de la yihad global. La pugna entre ambas organizaciones, junto con el posible retorno de combatientes extranjeros a sus países de origen ocuparán parte de la agenda de seguridad internacional tanto al corto como medio plazo.

\section{BIBLIOGRAFÍA}

ALONSO, J. Al-Qaeda en la Península Arábiga, Documento de investigación 1/2014, Colección: Grupos militantes de ideología radical y carácter violento. Región «Mena» y Asia Central, 2, Instituto Español de Estudios Estratégicos, http://www.ieee.es/Galerias/fichero/ docs_investig/2014/DIEEEINV012014_Al_Qaeda_PeninsulaArabica_JesusAlonsoBlanco.pdf. Consultado el 10/3/2014.

ALTUNA, S. ¿Hacia dónde se dirige el terrorismo yihadista en Túnez? La realidad del terrorismo yihadista en Túnez tras la ilegalización de Ansar Al-Sharia, 31 de marzo de 2015. http://www.ieee.es/Galerias/ fichero/docs_opinion/2015/DIEEEO27-2015_TerrorismoYihadista_Tunez_SergioAltuna.pdf. Consultado el 7/4/2015.

ALVARADO, D. La Yihad a nuestras puertas. La amenaza de Al Qaeda en el Magreb Islámico, Madrid, Akal. 2010.

ARGUMOSA, J. España y la seguridad del Sahel, Revista del Ejército, n. ${ }^{\circ}$ 889, Abril 2015, Madrid, Ministerio de Defensa, 2015. 
ARTEAGA, F. y GARCÍA, C. The Surge: el balance del Plan de Seguridad estadounidense en Irak durante 2007, Documento de Trabajo 2/2008, Real Instituto Elcano, http://www.realinstitutoelcano.org/ documentos/DT2008/DT2-2008_Arteaga_Garcia_The_Surge_Irak. pdf. Consultado el 10/12/2012.

ARTEAGA, F. Irak se rompe: la insurgencia suní se aprovecha del desgobierno de Maliki, Comentario Elcano 43/2014, Real Instituto Elcano, http://www.realinstitutoelcano.org/wps/wcm/connect/2772c 380445467d982caaf71c28b8853/comentario-Arteaga-Irak-se-rompe-insurgencia-suni-aprovecha desgobiernoMaliki.pdf?MOD=AJP ERES\&CACHEID=2772c380445467d982caaf71c28b8853. Consultado el 13/6/2014.

- Libia, entre el caos de la guerra civil y el agujero negro del Estado Islámico, Real Instituto Elcano, Opinión 17/2/2015, http://www. realinstitutoelcano.org/wps/portal/web/rielcano_es/ contenido?WCM_GLOBAL_CONTEXT=/elcano/elcano_es/zonas_ es/defensa $+y+$ seguridad/arteaga-libia-entre-el-caos-de-la-guerracivil-y-el-agujero-negro-del-estado-islamico\#. VX6oL_ntlHw. Consultado el 10/6/2015.

BARRANCOS, D. Los community managers del terror: la propaganda online de ISIS y su ofensiva sobre Irak, Documento de opinión 82bis/2014. Instituto Español de Estudios Estratégicos, http:// www.ieee.es/Galerias/fichero/docs_opinion/2014/DIEEEO82bis-2014_ISS_DavidBarrancos.pdf. Consultado el 10/8/2014.

BERENGUER, F. J. Las elecciones en Afganistán I, Documento informativo 8/2014, Instituto Español de Estudios Estratégicos, http:// www.ieee.es/Galerias/fichero/docs_informativos/2014/ DIEEEI08-2014_EleccionesAfganistan_FJBH.pdf. Consultado el $15 / 5 / 2014$.

CALVO, J. L. La caída de Mosul y el camino hacia una guerra regional en Oriente Medio, Mosaico: Blog sobre seguridad Internacional, 15/6/2014, http://www.seguridadinternacional.es/blog. mosaico/?q=es\%2Fcontent $\% 2$ Fla-ca $\%$ C3\%ADda-de-mosul-y-elcamino-hacia-una-guerra-regional-en-oriente-medio. Consultado el 20/6/2014.

CONDE, C. R. Expansión del yihadismo en el Sahel, Documento de opinión 27/2011, Instituto Español de Estudios Estratégicos, http://www.ieee.es/Galerias/fichero/docs_opinion/2011/DIEEEO27 _2011ExpansionYihadismoSahel.pdf. Consultado el 2/7/2015. 
DÍEZ, J. Yihadismo en África: amenaza, contexto y respuesta, Documento de Análisis 10/2015, 16 de febrero de 2015, http://www.ieee. es/Galerias/fichero/docs_analisis/2015/DIEEEA10-2015_YihadismoAfrica_JDA.pdf. Consultado el 20/4/2015.

ECHEVARRÍA, C. «The Sahel. A volatile Region», en Marquina, A.; Günter Brauch, H., The Mediterranean Space and its Borders. Geography, Politics, Economics and Environment, Madrid, UNISCI, 2001.

- Grupos terroristas operando en Siria, Documento de opinión 67bis/2014, Instituto Español de Estudios Estratégicos, http:// www.ieee.es/Galerias/fichero/docs_investig/2014/DIEEEINV04-2014_GruposTerroristasOperandoSiria_CEcheverria.pdf. Consultado el 22/6/2014.

ESCOBAR, J. J. Al Qaeda en el Magreb Islámico: del Sahel a España, Política Exterior, n. ${ }^{\circ}$ 134., Marzo-Abril. Madrid, 2010.

FUENTE, I. (2014). La inacabable guerra de Iraq, Documento de análisis 35/2014, Instituto Español de Estudios Estratégicos, http:// www.ieee.es/Galerias/fichero/docs_analisis/2014/DIEEEA35-2014_ InacabableGuerraIRAQ_IFC.pdf. Consultado el 14/7/2014.

INSTITUTE FOR ECONOMICS AND PEACE. Global Terrorism Index 2012 Capturing the Impact of Terrorism for the Last Decade, http:// www.visionofhumanity.org/sites/default/files/2012_Global_Terrorism_Index_Report.pdf. Consultado el 20/1/2013.

- Global Terrorism Index 2014. Measuring and understanding the impact of terrorism, http://www.visionofhumanity.org/sites/default/files/Global\%20Terrorism\%20Index\%20Report\%202014.pdf. Consultado el 16/1/2015.

INTERNATIONAL INSTITUTE FOR COUNTER-TERRORISM. IDC HERZLIYA. Cyber-Desk Review. Cyber-Terrorism Activities, 2013, http://www.ict.org.il/ResearchPublications/ICTCyberDeskReview/ tabid/492/Articlsid/1254/currentpage/1/Default.aspx. Consultado el $12 / 3 / 2014$

LABORIE, M. Informe sobre el progreso hacia la seguridad y la estabilidad en Afganistán (abril 2014), Documento de análisis 60/2014, Instituto Español de Estudios Estratégicos, http://www.ieee.es/ Galerias/fichero/docs_opinion/2014/DIEEEO60-2014_Informe_ ProgresoSeguridad_Afganistan_MLI.pdf. Consultado el 10/5/2014. 
LEFFLER, M. P. Retrospectiva del 11-S, Política Exterior, septiembre/ octubre, n. ${ }^{\circ} 143,2011$.

LORENZO-PENALVA, L. Yihad, martirio y evolución del terrorismo islámico global, Documento de opinión 106/2013, Instituto Español de Estudios Estratégicos, http://www.ieee.es/Galerias/fichero/docs_opinion/2013/DIEEEO106-2013_EvolucionTerrorismoIslamico_J. LorenzoPenalva.pdf. Consultado el 10/11/2013.

NAPOLEONI, L. El fénix islamista, Barcelona: Paidós, 2015.

NÚÑEZ, J. A. El delirio califal del Estado Islámico en Irak y Siria, en Política Exterior, septiembre/octubre 2014, n. ${ }^{\circ} 161$.

MARTÍN, J. Geopolítica del caos, Madrid, Catarata, 2015.

MESA, B. Siria, el nuevo dorado yihadista, Documento de opinión 15/2014, Instituto Español de Estudios Estratégicos, http://www. ieee.es/Galerias/fichero/docs_opinion/2014/DIEEEO15-2014_Siria_DoradoYihadista_B. Mesa.pdf. Consultado el 20/2/2014.

MORALES, A. Expansión mundial del terrorismo yihadista del Estado Islámico o Daesh", Documento de opinión 71/2015, Instituto Español de Estudios Estratégicos, http://www.ieee.es/Galerias/fichero/docs_opinion/2015/DIEEEO71-2015_ExpansMundial_ TerrorismoYihadista_A. Morales.pdf. Consultado el 10/8/2015.

ORGANIZACIÓN DE NACIONES UNIDAS. Pillay alerta sobre ejecuciones sumarias en la crisis actual en Iraq, 2014, http://www.un.org/ spanish/News/story.asp?newsID=29706\#. U5yUk5R_vko. Consultado el 14/6/2014.

OURDAN, D. ¿Hacia una yihad a gran escala?, Le Monde Diplomatique (ed), Atlas de las mundializaciones 2012, Valencia, Cybermonde, 2012.

REINARES, F. Reversión de la amenaza yihadista, Nueva Revista, n. ${ }^{\circ}$ 143, $2013 \mathrm{http} / /$ www.nuevarevista.net/articulos/reversion-de-laamenaza-yihadista. Consultado el 10/3/2014.

- Libia en la estrategia del Estado Islámico: ¿qué implicaciones para el norte de África y el sur de Europa?, Real Instituto Elcano, Comentario 12/2015 Elcano de 23/2/2015, http://www.realinstitutoelcano. org/wps/portal/web/rielcano_es/contenido?WCM_GLOBAL_CONTEXT=/elcano/elcano_es/zonas_es/comentario-reinares-libia-en-laestrategia-del-estado-islamico-implicaciones-norte-africa-sur-europa\#. VUdLatLtlHw. Consultado el 25/4/2015. 
RUIZ, F. J. Desarrollo del segundo Marrakech Security Forum, Documento informativo 03/2011, Instituto Español de Estudios Estratégicos, http://www.ieee.es/Galerias/fichero/docs_informativos/2011/DIEEEI03-2011SegundoMarrakechSecurityForum.pdf. Consultado el 3/6/2015.

RUPÉREZ, I. Estado islámico, califato universal, Es global, 2014, http://www.esglobal.org/estado-islamico-califato-universal/. Consultado el 10/8/2014.

SÁNCHEZ, P. Europa: una guerra total en el ¿flanco? sur, Documento de análisis 31/2015, Instituto Español de Estudios Estratégicos, http://www.ieee.es/Galerias/fichero/docs_analisis/2015/ DIEEEA31-2015_Europa_GuerraTotal_FlancoSur_PSH.pdf. Consultado el 3 de junio de 2015.

SÁNCHEZ, V. Viernes de terror, Revista Española de Defensa, julioagosto 2015.

SETAS, C. La frontera noroeste de Pakistán, 2001-2011: El fenómeno terrorista en las áreas tribales y sus implicaciones para la seguridad de Pakistán y la estabilidad regional, 2013, http://espacio.uned.es/ fez/eserv.php?pid=tesisuned: IUGM-Csetas\&dsID=Documento.pdf. Consultado el 16/1/2015.

THE USA NATIONAL INTELLIGENCE COUNCIL (2007). National Intelligence Estimate 2007, http://oai.dtic.mil/oai/oai?verb=getRec ord\&metadataPrefix $=$ html\&identifier $=$ ADA470324. Consultado el 22/8/2014.

TORRES, M. Siria y los yihadistas Easyjet, Mosaico: Blog sobre seguridad internacional, 2013, http://www.seguridadinternacional.es/ blog.mosaico/?q=es/content/siria-y-los-yihadistas-easyjet. Consultado el 8/1/2014. 